\title{
A study of median nerve cross sectional area in patients with mild to moderate idiopathic carpal tunnel syndrome
}

\author{
Dileep R. ${ }^{1, *}$, Benjamin Ramacha², Thomas Iype ${ }^{3}$ \\ ${ }^{1}$ Assistant Professor, ${ }^{2}$ Consultant, ${ }^{3}$ Professor \& HOD, Dept. of Neurology, ${ }^{1,3}$ Government Medical College, Thiruvananthapuram, \\ Kerala, ${ }^{2}$ Tiruvalla Medical Mission Hospital, Thiruvalla, Kerala, India \\ *Corresponding Author: \\ Email: drdileepramachandran@gmail.com
}

\begin{abstract}
Introduction: Carpal tunnel syndrome is the most common entrapment neuropathy and is caused by median nerve compression at the wrist as it passes through carpal tunnel.

Aim: To detect cross sectional area (CSA) of median nerve at the level of distal palmar crease and ratio of cross sectional area at level of proximal carpal tunnel to area $5 \mathrm{~cm}$ proximal to carpal tunnel using ultrasound.

Materials and Methods: Consecutive patients of age between 18 and 70 years, who presented with paraesthesia of hands (aggravated by holding or keeping hand elevated or with history of nocturnal worsening) and electrophysiological confirmed as mild to moderate idiopathic cases of carpal tunnel syndrome were included in the study. Baseline nerve conduction study was done as per standard protocol for carpal tunnel syndrome. Nerve ultrasound was done with high frequency linear-array transducer (7-14 Hz).

Results: 50 wrists in 30 Patients with CTS were studied. Females were more involved with a male: female ratio of 1:5. Mean age was 56.8 years (range 25-82 years).Majority of the cases were bilateral (67\%). Dominant hand was involved more (80\%) than non-dominant one. Most common symptoms were numbness (100\%) and paraesthesia on holding (90.91\%). On nerve ultrasound, all patients had CSA of median nerve at proximal carpal tunnel more than 10 square millimetre .The wrist fore-arm CSA ratio was more than 1 in all cases. Majority of the hands were having a cross sectional area 10-11.9 square millimetre and more than 16 square millimetre. We found correlation between CSA at distal palmar crease and median sensory conduction studies.

Conclusion

Our study affirms previous studies in demonstrating the usefulness of ultrasonography in diagnosing CTS. Median nerve Crosssectional area can be used for clinical screening of Carpal tunnel syndrome patients.
\end{abstract}

Keyword: Carpal tunnel syndrome, Cross sectional area, Wrist-ultrasound.

\section{Introduction}

Carpal tunnel syndrome (CTS) is an entrapment neuropathy caused by compression of median nerve at the level of wrist. ${ }^{1}$ Diagnosis of carpal tunnel syndrome can be made clinically and electro physiologically. Limitations of nerve conduction study are cost factors, more time taken for the test and lack of accessibility to most doctors.

Wrist ultrasonography can also be used for the diagnosis of CTS. ${ }^{2}$ Wrist-ultrasound may help in diagnosis of CTS, with the sensitivity approaching that of nerve conduction study. ${ }^{3}$ Wrist sonography with clinical evaluation and electrophysiology was more sensitive and specific than clinical evaluation or electrophysiology alone. ${ }^{4-6}$ Advantages of wrist-ultrasound in CTS is that it is widely available, relatively less expensive, noninvasive, takes less time, and better depiction of pathology like tenosynovitis.

Our study aimed 1) To find cross sectional area (CSA1) of median nerve at the level of distal palmar crease(proximal part of carpal tunnel); 2) To find ratio of CSA1 to median nerve cross sectional area at a point 5 $\mathrm{cm}$ proximally (CSA2); 3) Find any correlation between nerve conduction study values and wrist-ultrasound values.

\section{Materials and Methods}

The study was conducted in Department of Neurology, Government Medical College, Thiruvananthapuram after getting the approval from the human ethics committee and was a six months period study.

We recruited consecutive patients of age between 18 and 70 years, who presented with paraesthesia of hands (increased by holding things or with history of increase in symptoms during night) and confirmed by nerve conduction study as mild to moderate idiopathic carpal tunnel syndrome for the study. Probable secondary causes of CTS (rheumatoid arthritis, hypothyroid, acromegaly, and diabetes mellitus), pregnant ladies, previous wrist surgery and wrist fracture cases were excluded.

Baseline nerve conduction study was done with Nicolet Viking system EMG machine measuring median distal motor latency (DML), amplitude of compound muscle action potential (CMAP), Sensory peak latency and amplitude of median sensory nerve action potential (SNAP). ${ }^{7}$ Cases were classified into mild, moderate and severe carpal tunnel syndrome cases based on AANEM (American Association of Neuromuscular \& Electrodiagnostic Medicine) criteria. ${ }^{8}$ Cases with only 
sensory latency prolongation more than 3.5 milliseconds(ms) were classified as mild CTS. Moderate CTS cases were classified as those having sensory latency prolongation along with distal motor latency prolongation (more than $4.2 \mathrm{~ms}$ ) with normal motor and sensory amplitudes.

Nerve ultrasound was done with high frequency lineararray transducer $(7-14 \mathrm{~Hz})$. Patients were seated for ultrasound examination with arms supinated and extended. Wrists were rested on a hard flat surface. We looked for median nerve in transverse plane at two points, first at the level of distal palmar crease and second in forearm, $5 \mathrm{~cm}$ proximal to the first site. Crosssectional area at the level of distal palmar crease (CSA1) and cross-sectional area at a point $5 \mathrm{~cm}$ proximal (CSA2) were measured. Continuous tracing technique was done by tracing the inner border of the thin hyper echoic epineural rim. Serial measurement was done three times and average value was calculated. Ratio between two CSA (Wrist Forearm Ratio, WFR) was calculated.

Statistical analysis was done with SPSS.

\section{Results}

50 wrists in 30 Patients with CTS were studied. Females were more involved with a male: female ratio of 1:5. Mean age was 56.8 years (range $25-82$ years).

$67 \%$ of cases were bilateral. $80 \%$ had dominant hand involvement among symptoms; numbness (100\%) and paraesthesia on holding $(90.91 \%)$ were most common ones.

Table 1: Electrophysiologic data

\begin{tabular}{|l|c|}
\hline \multicolumn{1}{|c|}{ Electrophysiological Parameters } & Mean \\
\hline Sensory Peak Latency & $4.79 \pm 0.5$ millisecond \\
\hline SNAP amplitude & $32.82 \pm 2.97$ microvolt \\
\hline Distal motor latency & $5.59 \pm 0.95$ millisecond \\
\hline CMAP amplitude & $10.35 \pm 1.09$ millivolt \\
\hline
\end{tabular}

On nerve ultrasound, all patients had CSA of median nerve at level of distal palmar crease more than 10 square millimetre The wrist fore-arm ratio was more than 1 in all cases. Mean values are given in table 2.

Table 2: Nerve ultrasound data

\begin{tabular}{|l|c|}
\hline \multicolumn{1}{|c|}{ Ultrasound parameters } & $\begin{array}{c}\text { Mean value } \\
\text { (in square millimetre) }\end{array}$ \\
\hline $\begin{array}{l}\text { CSA of median nerve at level of distal } \\
\text { palmar crease }\end{array}$ & $14.56 \pm 4.51$ \\
\hline Wrist forearm ratio & $1.85 \pm 0.54$ \\
\hline
\end{tabular}

Majority of the hands were having a cross sectional area 10-11.9 square millimetres and more than 16 square millimetres (Table 3).

Table 3: Distribution of hands according to CSA severity

\begin{tabular}{|l|c|c|}
\hline $\begin{array}{c}\text { Range of CSA at Proximal CT } \\
\text { (square millimetre) }\end{array}$ & $\begin{array}{c}\text { Number of } \\
\text { hands }\end{array}$ & Percentage \\
\hline $10-11.9$ & 15 & 30 \\
\hline $12-13.9$ & 12 & 24 \\
\hline $14-15.9$ & 8 & 16 \\
\hline More than16 & 15 & 30 \\
\hline
\end{tabular}

We found correlation between CSA at distal palmar crease and median sensory conduction studies (Table 4).

Table 4: Correlation between CSA and electrophysiologic parameters

\begin{tabular}{|l|l|c|}
\hline \multicolumn{2}{|c|}{ Correlation between } & $\begin{array}{c}\text { Correlation } \\
\text { coefficient }\end{array}$ \\
\hline Distal motor latency & CSA at distal palmar crease & -0.053 \\
\hline Distal motor latency & PROXIMAL/DISTAL CSA & -0.121 \\
\hline Sensory peak latency & CSA at distal palmar crease & 0.352 \\
\hline Sensory peak latency & Proximal/Distal CSA & 0.181 \\
\hline CMAP amplitude & CSA at distal palmar crease & 0.351 \\
\hline CMAP amplitude & Proximal/Distal CSA & 0.233 \\
\hline SNAP amplitude & CSA at Proximal CT & -0.109 \\
\hline SNAP amplitude & Proximal/Distal CSA & -0.095 \\
\hline
\end{tabular}




\section{Discussion}

An enlargement of median nerve at proximal carpal tunnel (CSA $>10$ square millimetre) was seen in all our patients which was similar to other studies of sonography in CTS. ${ }^{9-11}$

In our study, the wrist forearm ratio was more than 1.4.Studies suggest that measurement of cross-sectional area at forearm and calculation of a distal proximal ratio will improve the sonographic diagnosis of CTS. ${ }^{12-}$ ${ }^{14}$ So measuring a proximal CSA and calculating wrist fore arm ratio will be an additional aid in sonographic evaluation of CTS patients.

We found correlation between CSA at proximal carpal tunnel and median sensory conduction studies. But in other similar studies, all nerve conduction study parameters showed a correlation with ultrasound findings. ${ }^{15,16}$

Our study had certain limitations: a) There was no control group b) No other US parameters were evaluated c) Measurements were performed by a single observer.

\section{Conclusion}

Our study confirms the use of sonography in diagnosing CTS. Cross-sectional area measurements can be used for evaluation of Carpal tunnel syndrome. Each hospital should establish its own range of reference measurements .Further standardization of the sonographic technique and prospective evaluation is needed.

\section{References}

1. Olney RK. Carpal tunnel syndrome: complex issues with a "simple" condition. Neurol 2001;56:1431-32.

2. Wiesler ER, Chloros GD, Cartwright MS, Smith BP, Rushing J, Walker FO. The use of diagnostic ultrasound in carpal tunnel syndrome. J Hand Surg Am 2006;31:726-32.

3. Lee D, van Holsbeeck M, Janevski PK, Ganos DL, Diagnosis of carpal tunnel syndrome: ultrasound versus electromyopathy. Radiol Clin North Am 1999;37:859-72.

4. Duncan I, Sullivan P,Buchberger W, Schön G, Strasser $\mathrm{K}$, Jungwirth W. High-resolution ultrasonography of the carpal tunnel. J Ultrasound Med 1991;10:531-37.
5. Koyuncuoglu HR, Kutluhan S, Yesildag A, Oyar O, Guler K, Ozden A. The value of ultrasonographic measurement in carpal tunnel syndrome in patients with negative electrodiagnostic tests. Eur J Radiol 2005;56:365-69.

6. Lee D, van Holsbeeck MT, Janevski PK, Ganos DL, Ditmars DM, Darian VB. Diagnosis of carpal tunnel syndrome: ultrasound versus electromyography. Radiol Clin North Am 1999;37:859-72.

7. C. K. Jablecki, M. T. Andary, M. K. Floeter. Practice parameter: Electrodiagnostic studies in carpal tunnel syndrome: Report of the American Association of Electrodiagnostic Medicine, American Academy of Neurology, and the American Academy of Physical Medicine and Rehabilitation Electrodiagnostic Medicine. Neurol 2002;58;1589.

8. Padua L, Lo Monaco M, Padua R, Gregori B, Tonali P. Neurophysiological classification of carpal tunnel syndrome: assessment of 600 symptomatic hands. Italian J Neurol Sci 1997;18(3):145-50.

9. Bodner G. Nerve compression syndromes. In: Peer S, Bodner G, eds: High-resolution sonography of the peripheral nervous system. 2nd ed. Spinger Verlag Berlin Heidelberg, 2008;4:72-122.

10. Buchberger W, Schon G, Strasser K, Jungwirth W. Highresolution ultrasonography of the carpal tunnel. $J$ Ultrasound Med 1991;10:531-7.

11. Buchberger W, Judmaier W, Birbamer G, Lener M, Schmidauer C. Carpal tunnel syndrome: diagnosis with high-resolution sonography. AJR Am J Roentgenol 1992;159:793-98.

12. Hobson-Webb LD, Massey JM, Juel VC, Sanders DB. The ultrasonographic wrist-to-forearm median nerve area ratio in carpal tunnel syndrome. Clin Neurophysiol 2008; 119:1353-1357.

13. Hobson-Webb LD, Padua L. Median nerve ultrasonography in carpal tunnel syndrome: findings from two laboratories. Muscle Nerve 2009 40:94-7.

14. Klauser AS, Halpern EJ, De Zordo T. Carpal tunnel syndrome assessment with US: value of additional crosssectional area measurements of the median nerve in patients versus healthy volunteers. Radiol 2009;250:17177

15. Domanasiewicz A, Koszewicz M, Jabłecki J. Comparison of the diagnostic value of ultrasonography and neurography in carpal tunnel syndrome. Neurologia $i$ neurochirurgia polska 2009;43,5:433-38

16. Shawn C. Roll, Kevin D. Evans, Xiaobai Li, Miriam Freimer, Carolyn M. S J. Screening for Carpal Tunnel Syndrome Using Sonography. Ultrasound Med 2011;30(12):1657-67. 